\title{
Impact of nano zero valent iron on tetracycline degradation and microbial community succession during anaerobic digestion
}

Pan, Xiaofang; Lv, Nan; Li, Chunxing; Ning, Jing; Wang, Tao; Wang, Ruming; Zhou, Mingdian; Zhu, Gefu

Published in:

Chemical Engineering Journal

Link to article, DOI:

10.1016/j.cej.2018.11.135

Publication date:

2018

Document Version

Peer reviewed version

Link back to DTU Orbit

Citation (APA):

Pan, X., Lv, N., Li, C., Ning, J., Wang, T., Wang, R., Zhou, M., \& Zhu, G. (2018). Impact of nano zero valent iron on tetracycline degradation and microbial community succession during anaerobic digestion. Chemical Engineering Journal, 359, 662-671. https://doi.org/10.1016/j.cej.2018.11.135

\section{General rights}

Copyright and moral rights for the publications made accessible in the public portal are retained by the authors and/or other copyright owners and it is a condition of accessing publications that users recognise and abide by the legal requirements associated with these rights.

- Users may download and print one copy of any publication from the public portal for the purpose of private study or research.

- You may not further distribute the material or use it for any profit-making activity or commercial gain

- You may freely distribute the URL identifying the publication in the public portal 
1 Impact of nano zero valent iron on tetracycline degradation and microbial community succession during anaerobic digestion

4 Xiaofang Pan ${ }^{1}$, Nan Lv ${ }^{1,2}$, Chunxing Li ${ }^{1,3}$, Jing Ning ${ }^{1,2}$, Tao Wang ${ }^{1,2}$, Ruming

$5 \quad$ Wang ${ }^{1,2}$, Gefu Zhu ${ }^{1,2 *}$

$6{ }^{1}$ Key Laboratory of Urban Pollutant Conversion, Institute of Urban Environment,

7 Chinese Academy of Sciences, Xiamen 361021, China

$8 \quad{ }^{2}$ University of Chinese Academy of Sciences, Beijing 100049, China

$9 \quad{ }^{3}$ Department of Environmental Engineering, Technical University of Denmark, Kgs.

10 Lyngby DK-2800, Denmark

11

12

13

14

15

*Corresponding author.

E-mail: gfzhu@iue.ac.cn; Phone: 86-592-6190790; Fax: 86-592-6190790 


\section{Abstract}

Supplementing nano zero valent iron (nZVI) is an attractive technology for wastewater treatment due to its advantages in accelerating the hydrolysis,

19 fermentation and anaerobic digestion (AD) process. In this present study, nZVI was

20 added to investigate its effects on enhancing tetracycline (TC) wastewater anaerobic

21 treatment and the changes of microbial community, especially for underestimated

22 syntrophic-methanogenic associations. The TC concentrations were 1, 10, 30, 50, 80,

23100 and $150 \mathrm{mg} / \mathrm{L}$ with $0.38 \mathrm{~g} \mathrm{nZVI}$ (with iron $\mathrm{g} / \mathrm{g} \mathrm{VS}$ of 0.50 ) complemented into

24 reactors. Results revealed that nZVI could enhance AD process in both control and

25 TC dosed systems, and the promoting effect on methanogenesis was more significant

26 in systems of high concentration TC, with 100 and $150 \mathrm{mg} / \mathrm{L}$. In addition, cumulative

$27 \mathrm{CH}_{4}$ production for all $\mathrm{TC}$ added systems without $\mathrm{nZVI}$ were higher than the control

28 indicating TC had positive effect instead of expected negative effect on AD process,

29 high TC concentration of 100 and $150 \mathrm{mg} / \mathrm{L}$ only affecting the increase factor rather

30 than causing inhibitory effect. After digestion, TC was largely removed in

31 with/without nZVI systems. And also, nZVI evidently altered the bacterial and

32 methanogenic community structure, with an increase abundance of

33 syntrophic-methanogenic associations (Syntrophobacterales and Methanosarcinales)

34 and resulting in the enhancement of methane generation. This research provides an

35 efficient method for TC wastewater anaerobic treatment. 
36 Key words: Anaerobic digestion, Nano zero valent iron, Tetracycline, Microbial

37 community, Syntrophic-methanogenic associations. 


\section{Introduction}

With the rapid development of industry and agriculture, incrementally large amounts of antibiotics have been applied in our society. And the antibiotics were extensively obtained much attention for their acute and chronic toxicity and side-effect to human beings and other environmental organisms. It was reported that the discharge of pharmaceutical wastewater has been considered as one of the most important sources of antibiotics in surface and groundwater, which led to huge potential human health effects [1]. Especially for tetracycline (TC), its excellent inhibitory effect on different bacterium and important new use resulted in its extensively application and in turn much higher production. As the result, the concentration of TC in effluents produced by hospital and TC production industry is higher than $100 \mathrm{mg} / \mathrm{L}$, which was much higher than concentration of TC in wastewater treatment plants (WWTPs) [2].

50 Therefore, the disposal of wastewater containing TC was of great importance and 51 challenge.

52 Nowadays, the most main treatment methods for degradation antibiotics are

53 physical, chemical and biological technologies. Biological treatment has turned out to 54 be a promising and economical approach to deal with various recalcitrant pollutants $55[3,4]$. In addition, as the high biochemical oxygen demand (BOD), chemical oxygen demand (COD), total suspended solids (TSS) and wide range of $\mathrm{pH}$ from 1 to 11 of pharmaceutical wastewater, physical and/or chemical methods are not the suitable 
choice for their low dissolved COD removal efficiency and high consumption of chemicals [5]. Therefore, biological anaerobic method was verified as the optimal choice for its advantage in energy generation with degradation of organic matters and antibiotics or via microorganism [6]. A combination anaerobic-aerobic treatment system was also developed for removing organic matter from the high-strength pharmaceutical wastewater, and it revealed that antibiotics removal process was mainly occurred in AD phase [1]. Previous study had pointed out that AD process can effectively treat some of by-end products of pharmaceutical manufacturing wastewaters, such as TC, with TC removal rate from $14 \%$ to $89 \%$ [7]. However, anaerobic treatment is a unique process that requires sequential degradation steps (hydrolysis, acidogenesis, acetogenesis and methanogenesis) by several bacterial and archaeal groups. While, antimicrobials may directly inhibit biological activities of these microorganisms even deteriorate and collapse anaerobic processes [8]. Lu et al. [9] found that the presence of TC $(250 \mu \mathrm{g} / \mathrm{L})$ had a large negative effect on $\mathrm{CH}_{4}$ and $\mathrm{CO}_{2}$ production, and indicated that methanogenesis process was sensitive to $\mathrm{TC}$ presence with no insensitivity for acidogenesis. It indicated anaerobic biological method also has drawbacks for higher TC wastewater treatment efficiency. Therefore, new technology on the basis of anaerobic biological method was required to resolve this drawback.

Recent research found that starch-nZVI (nano zero valent iron)/ZVI could remove with adsorption, degradation flocculation, oxidation and reduction $[10,11]$. 
ZVI can act as reducing agent which helps create an enhanced anaerobic environment to improve the performance of anaerobic process and maintain a stable and favorable

81 condition for methanogenic archaea $[12,13]$. In addition, the nZVI addition presented many advantages such as acting as electron donor, increase the total consumption of hydrogen methanogens and activity, release $\mathrm{Fe}^{2+}$ into the anaerobic system and participating in the synthesis of the key enzymes, provide for iron element serving as trace element for methanogens [12], optimizing the structure of microbial population, changing the hydrolysis fermentation types and promoting the acetic acid content $[12$, 14]. Based on above, supplementing nZVI into anaerobic TC wastewater treatment system might be an effective technique for both TC removal and organic matters degradation. And the variations of relative abundance of microbial communities affected TC removal and organic matters degradation [5], especially for changes of syntrophic bacteria which are closely related to methanogens and determined the efficiency of $\mathrm{AD}$, are not currently well understood in these systems. It had reported that supplementation of ZVI has a positive influence on the syntrophic microorganism in an organic fraction of municipal solid waste $\mathrm{AD}$ reactor, and the syntrophic interaction of acetogens and methanogens is critical to the performance of anaerobic antibiotics (incudes TC) treating reactors [15]. In addition, the relationship between TC concentration and anaerobic performance in nZVI as additive systems, which related to the tolerable concentration when apply this technology in practice, is still unclear. As such, comprehensive research into this system is required to evaluate the 
performance of $\mathrm{AD}$ process, $\mathrm{TC}$ degradation and variation of microbial structure,

101 focusing on the relationship between syntrophic associations' succession and

102 experimental conditions.

103 Therefore, the objectives of this research were two aspects: i) to develop an

104 anaerobic technology for treating TC wastewater efficiently by adding nZVI and

105 investigate the promoting effect of nZVI on AD process and TC removal in different

106 TC dosing reactors; ii) to understand how the nZVI and TC change the structure and

107 relative abundance of microbial communities especially for syntrophic-methanogenic

108 associations. Therefore, nZVI was served as an additive and supplemented into

109 anaerobic treatment systems with different concentrations of TC. The $\mathrm{pH}$ values, ORP

110 values, and COD removal rates and TC removal rates were determined for evaluating

111 the operation of anaerobic systems. And also, the methane production in each reactor

112 was calculated. Illumina MiSeq sequencing was operated to characterize the

113 microorganism succession and changes in microbial diversity. This research can give

114 guidance for TC wastewater treatment by anaerobic biological technology. And also,

115 functional anaerobic microbial communities obtained in this study can provide data

116 support for deeply understanding of anaerobic microbial metabolism.

\section{2. Materials \& Methods}

\section{$118 \quad 2.1$ Chemicals and stock solution}

119 Iron powder $(99.9 \%$ metals basis, $100 \mathrm{~nm})$ was obtained from Sigma chemicals. The 
121 were supplied by glucose (99.8\%, Sinopharm Chemical Reagent Co., Ltd), and stock

122 solution was prepared with $10 \mathrm{~g} / \mathrm{L}$. In addition, $\mathrm{H}_{2} \mathrm{O}$ was prepared for consuming 123 oxygen.

\subsection{Inoculum and Medium} disrupted sludge [16]. Therefore, granular sludge, obtained from a mesophilic up-flow anaerobic sludge blanket (UASB) digester $(\mathrm{pH}=7.4 \pm 0.2)$ for critic-acid wastewater AD in Green Environmental Technology Company, Xuzhou, was served as inoculum in

129 this study. The average diameter of studied granules is about $1.5 \pm 0.3 \mathrm{~mm}$. The volatile solid (VS) and total solid (TS) were $51.08 \mathrm{~g} / \mathrm{L}$ and $60.80 \mathrm{~g} / \mathrm{L}$, measured referring to

131 standard method [17]. The basic anaerobic medium was prepared as described in 132 previous study [18].

\section{$133 \quad 2.3$ Operation of anaerobic batch reactor systems}

Experimental set-up for anaerobic biodegradation was revised from Angelidaki

135 and Sanders (2004) [18]. The batch experiments were performed in $310 \pm 1 \mathrm{~mL}$ serum

136 bottles in triplicate with working volume of $100 \mathrm{~mL} .15 \mathrm{~mL}$ granular sludge, $25 \mathrm{~mL}$

137 basic anaerobic medium $(\mathrm{pH}=7.0), 50 \mathrm{~mL}$ glucose stock solution (synthesis of TC

138 wastewater with final concentration of $5000 \mathrm{mg} \mathrm{COD} / \mathrm{L}$ in batch reactors and $\mathrm{F} / \mathrm{M}$ of

$1390.65 \mathrm{~g} \mathrm{COD} / \mathrm{g} \mathrm{VS}), 1 \mathrm{~mL} \mathrm{Na} 2 \mathrm{~S} \cdot 9 \mathrm{H}_{2} \mathrm{O}(2.5 \%)$ distilled water were added to serum 
140 bottles, and the rest of $9 \mathrm{~mL}$ consisted of TC solution and distilled water. In order to

141 take both low concentration of TC, like in municipal wastewater and high

142 concentration of TC in pharmaceutical wastewater into consideration, two sets of

143 batch experiments were conducted, with the TC concentration of $0,1,10,30,50,80$

$144 \mathrm{mg} / \mathrm{L}$ and $0,100,150 \mathrm{mg} / \mathrm{L}$, which stand for the concentration of TC in WWTPs and

145 antibiotics producing industries effluents, and finally, the reactors were flushed with

$14699.99 \% \mathrm{~N}_{2}$ for 15 minutes. Additionally, in order to reveal the impact of nZVI on

147 anaerobic system, $0.38 \mathrm{~g}$ iron powder was complemented into half of experimental

148 reactors, with the ratio of iron $\mathrm{g} / \mathrm{g} \mathrm{VS}$ of 0.50 , which was proved as optimized value

149 in previous study [19]. For maintaining anaerobic condition, serum bottles was flushed

150 with $99.99 \% \mathrm{~N}_{2}$ for 15 minutes and then sealed with rubber stoppers and aluminum caps.

151 Batch reactors were incubated in a thermostatic shaker at $37 \pm 0.5^{\circ} \mathrm{C}$ and $160 \mathrm{rpm}$.

152 During the incubation, gas production was monitored every day.

\section{$153 \quad 2.4$ Analytical methods}

154 The analysis of methane content was performed via gas chromatography (FULI

155 GC9790II) with column of TDX-01 (2m long and 3mm in inner diameter). Argon

156 serves as carrier gas. The temperature of packed column, detector and injection port is

157 set to $120{ }^{\circ} \mathrm{C}, 160{ }^{\circ} \mathrm{C}$ and $160{ }^{\circ} \mathrm{C}$ respectively.

158 The cumulative volume of $\mathrm{CH}_{4}$ generated in serum bottle is calculated by

159 multiplying the headspace volume $(260 \mathrm{~mL})$ by the $\mathrm{CH}_{4}$ percentage $\left(\mathrm{mLCH}_{4} / \mathrm{mL}\right)$ in 
160 the headspace as determined by GC analysis. It must be noted that gas samples taken

161 from batch reactors should equilibrate in batch reactors which make the pressure in

162 batch reactors have been taken into consideration. In addition, the obtained value of

163 cumulative $\mathrm{CH}_{4}$ production was normalized in Standard Temperature and Pressure

164 (STP) conditions $\left(0^{\circ} \mathrm{C}\right.$ and $\left.1 \mathrm{~atm}\right)$ according to ideal gas law $(\mathrm{PV}=\mathrm{nRT})$. The methane

165 production assay is referenced to sample mass or chemical oxygen demand

$166\left(\mathrm{NmLCH}_{4} / \mathrm{g} \mathrm{VS}\right.$ or $\left.\mathrm{NmLCH}_{4} / \mathrm{g} \mathrm{COD}\right)[18]$.

167 COD, $\mathrm{pH}$ value and reduction-oxidation potential (ORP) were determined

168 according to Standard Methods [17]. The concentrations of TC in liquid and sludge

169 samples were measured by LC/MS (ABI 6500), the detailed protocol referred to

170 Cetecioglu et al. [20].

\subsection{DNA extraction and Illumina MiSeq sequencing process}

173 samples of each reactor was extracted from $0.5 \mathrm{~g}$ of sludge, after centrifuging of 50

174 mL sludge for 10min at $12000 \mathrm{rpm}$, using Fast DNA Spin Kit for Soil (MP bio, USA).

175 Detailed procedure of DNA extraction was followed the manufacturer's instruction.

176 The DNA concentrations were determined by Nano drop 1000 (Thermo Scientific). 
181 (5'-YCCGGCGTTGAVTCCAATT-3') for the V4-V5 region of 16S rRNA gene [22],

182 separately. The mixtures of the amplicons from two sets of primers were used for

183 sequencing on Illumina MiSeq platform following standard protocols, which were

184 performed in Major bio China.

\subsection{Modified Gompertz model}

The modified Gompertz equation is shown as follows:

$$
P=A \times \exp \left\{-\exp \left[\frac{U e}{A}(\lambda-t)+1\right]\right\}
$$

191

Where

$$
\mathrm{P} \text { - cumulative methane production, } \mathrm{N} \mathrm{mL} / \mathrm{g} \text { VS at any digestion time } \mathrm{t} \text {; }
$$

$$
\text { A - methane yield potential, } \mathrm{N} \mathrm{mL/g} \mathrm{VS}
$$

$\mathrm{U}$ - maximum rate of methane production, $\mathrm{N} \mathrm{mL} /(\mathrm{gVS} \bullet \mathrm{d})$;

$$
\text { e - mathematical constant (2.718282). }
$$


200 kinetic constant of $\mathrm{CH}_{4}$ production rate will be expressed by $\mathrm{U}$ constant

\subsection{Statistical analysis}

All assays were performed in triplicate. Data analysis was done with EXCEL 2017.

203 Additionally, Origin 8.0 was applied for production of graphics. To compare the

204 differences in microbial communities between nZVI added reactors, TC dosed

205 reactors and blank, a one-way analysis of variance (ANOVA) was used. Analyses

206 were conducted on the free online platform of Majorbio I-Sanger Cloud Platform

207 (www.i-sanger.com) . A $p$ value less than 5\% was considered to be statistically

208 significant.

209 3. Results and discussion

\section{$210 \quad 3.1$ Performances in pH, ORP and COD removal}

211 As taking liquid sample during the process of digestion operation can significant

212 impact the $\mathrm{CH}_{4}$ production and substrate consumption in batch reactors with work

213 volume of $100 \mathrm{~mL}$, the $\mathrm{pH}$ and ORP values were only measured at the end of

214 digestion to evaluate the final environmental condition of each system. The $\mathrm{pH}$ values

215 in batch reactors with nZVI addition were significant higher than those without

216 adding nZVI systems. It indicated that adding nZVI could release the volatile fatty

217 acids (VFAs) accumulation, which is beneficial to AD process [25]. For batch reactors

218 with TC concentration range of $0-80 \mathrm{mg} / \mathrm{L}$, the $\mathrm{pH}$ variation between reactors with 
219 and without nZVI addition was slight, while it was significantly varied with TC

220 concentration of 100 and $150 \mathrm{mg} / \mathrm{L}$. It means that nZVI supplementation had

221 significant positive effect on AD process in the systems with high TC concentration.

222 These results coincided with the COD removal rates in these reactors, nZVI added

223 systems presented higher COD removal rates than those without nZVI systems at each

224 level of TC concentration. Similarly, the large difference between with and without

225 nZVI systems was occurred under high TC concentration of 100 and $150 \mathrm{mg} / \mathrm{L}$. The

$226 \mathrm{nZVI}$ dosed reactors maintained the $\mathrm{pH}$ at the level of $7.3-8.3$, which might be due to

227 that the nZVI served as an acid buffer by the dissociation of $\mathrm{Fe}^{0}$ and $\mathrm{Fe}^{3+}$ (reaction 1 ,

228 2, 3) [26, 27].

$$
8 \mathrm{H}^{+}+4 \mathrm{Fe}^{0}+\mathrm{CO}_{2}=\mathrm{CH}_{4}+4 \mathrm{Fe}^{2+}+2 \mathrm{H}_{2} \mathrm{O}
$$

$\mathrm{Fe}^{3+}+3 \mathrm{H}_{2} \mathrm{O}=\mathrm{Fe}(\mathrm{OH})_{3}+3 \mathrm{H}^{+}$

$$
\mathrm{Fe}+2 \mathrm{H}_{2} \mathrm{O}=\mathrm{Fe}^{2+}+\mathrm{H}_{2}+2 \mathrm{OH}^{-}
$$

232 In addition, the low $\mathrm{pH}$ values (5.2-5.5) occurred in blank 2 system and systems with

233 TC concentration of 100 and $150 \mathrm{mg} / \mathrm{L}$, and their COD removal rates and cumulative

234 methane yields were also low. These could be explained by that the low $\mathrm{pH}$ condition

235 influenced the growth of methanogens.

236 Coincidentally, the ORP values in nZVI dosed reactors were higher than those in

237 without nZVI added systems. However, the result was contrary to previous outcomes

238 that nZVI could lower the ORP value to maintain a reductive condition for

239 methanogenic archaea [14]. Nevertheless, the ORP values in nZVI added systems 
240 were $-314 \sim-261 \mathrm{mV}$, which still meet the anaerobic requirement for methanogenesis

$241(\mathrm{ORP}<-200 \mathrm{mV})$. Among the nZVI supplemented with different TC concentration

242 systems, the ORP values from mixed liquid slurry ranged from -261 to $-296 \mathrm{mV}$ at the

243 end of $\mathrm{AD}$, suggesting that all the dissolved iron species was in the ferrous form (e.g.,

$244 \mathrm{Fe}^{2+}$ or $\mathrm{Fe}(\mathrm{OH})^{+}$), which may lead to its adsorption and precipitate (e.g., for forming

$245 \mathrm{FeS}$ ) in AD [27]. The increased ORP value also might have relationship with

246 fermentation type occurred in nZVI systems. And, considering the $\mathrm{pH}$ values, the

247 fermentation type in nZVI added systems might be butyrate fermentation with ORP of

$248-350 \sim-200 \mathrm{mV}$ and $\mathrm{pH}$ value $>5.8$. Although the concentration of butyrate had been

249 not determined in batch reactors because of the high COD removal rate, we could

250 deduce that butyrate was main intermediates in nZVI added systems owing to the

251 increase abundance of Syntrophus containing groups for syntrophic butyrate-oxidizing

252 (Fig. 3).

253 It was obvious that COD removal rates in blank 1 and non-nZVI systems with

254 TC concentration of $1-80 \mathrm{mg} / \mathrm{L}$ were quite similar to those with nZVI systems, with

255 the values approximately of 92\% - 96\%. This also illustrated that adding nZVI had

256 little impact on COD removal rate under low TC concentration $(0-80 \mathrm{mg} / \mathrm{L})$, which

257 might due to the COD removal rates in non-nZVI reactors had reached a relative high

258 level. Interesting, TC addition ( $0-80 \mathrm{mg} / \mathrm{L})$ had not showed evidently negative effect

259 on COD removal rate, this result was corresponded to methane production in these

260 reactors. The COD removal rate in blank 2 was quite lower than that in blank 1, which 
261 means that activity of anaerobic bacteria in blank 2 was much lower than that in blank

262 1. But the high removal rate of COD in reactor of blank 2 with nZVI revealed that

263 nZVI could enhance AD and active anaerobic microbes. The similar result occurred in

264100 and $150 \mathrm{mg} / \mathrm{L}$ TC added systems, COD removal rates were only $50.04 \%$ and

$26549.18 \%$, respectively, while in these two levels of TC with nZVI added systems, the

266 COD removal rates reached as high as $94.80 \%$ and $94.18 \%$. These results indicated

267 that $\mathrm{nZVI}$ could enhance AD process in systems containing high concentration of TC.

268 As mentioned above, this might due to that nZVI can be used as electron donor,

269 accelerating the hydrolysis and fermentation process and increase the methanogenic

270 activity, release $\mathrm{Fe}^{2+}$ into the anaerobic system and participate in the synthesis of the

271 key enzymes [12].

\section{$272 \quad 3.2$ The methane production kinetics and TC removal}

273 To deeply investigate the effect of adding nZVI on AD process and TC

274 degradation performance, the cumulative methane production and TC removal

275 efficiency were tested and the methane yields were also listed in Table 1. Compared

276 with the non-added nZVI systems at same TC concentration level, adding nZVI could

277 obviously enhance the methane production. It was also verified by the change of

278 increase factors that higher TC concentration gives higher increase factor. Meanwhile,

279 an interesting result can be observed that $\mathrm{CH}_{4}$ production in batch reactors with $\mathrm{TC}$

280 have higher cumulative methane yield than that of blank reactors, which means that 
281 TC has positive effect on methane production. And this result was contrary to some

282 previous studies. In fact, TC can inhibit the AD performance via influencing the

283 metabolism, growth and viability of various microorganisms. Previous studies

284 delivered different results due to differences in the setup (batch reactor $v s$ continuous

285 process), substrate utilization (e.g. manure, activated sludge, biogas plant fermenter

286 content), initial compound concentration and duration of the experiment. Some

287 researchers also reported that TC showed no relevant change in methane generation

288 compared to the control at exposed dose of $10 \mathrm{mg} / \mathrm{L}$, furthermore, it also stated that TC

289 had no significant effects on AD performance [16], whereas other studies revealed a

290 decrease of the biogas and/or methane yield [20]. Shi et al., [28] found biogas

291 production decreased by $25 \%$ at TC dose of $50 \mathrm{mg} / \mathrm{L}$. The COD removal rates

292 between blank and experimental reactors with TC concentration lower than $80 \mathrm{mg} / \mathrm{L}$

293 were quite similar (seeing Table 1 again), but the increased $\mathrm{CH}_{4}$ production in TC

294 added systems than blank means that TC enhanced the proportion of methane in

295 biogas, and this result might cause by the microbes variation (discussed in 3.3).

296 Owing to the fact that the TC could be applied to generate biogas during AD

297 process, the specific methane production was calculated and the data were simulated

298 by utilizing modified Gompertz model. The predicted curves for specific $\mathrm{CH}_{4}$ yield

299 along with digestion time fit well with observed values in each system, with $\mathrm{R}^{2}>0.90$

300 (Fig.1, Table 2). It revealed that nZVI had positive impact on methane production in

301 both blank and TC added systems, with higher methane yield potential. These results 
could be explained by the recent research outcomes that adding nZVI in AD improved methane yield due to the release of hydrogen during nZVI corrosion/oxidation, which

304 can serve as the electron donor for methanogens [12]. On the other side, the rapid

311 it also give an reason for the lower maximum methane production rate (U) in system

312 with nZVI than without nZVI [12]. Some reports pointed out that nZVI addition could

313 inhibit methanogenesis for its disruption of cell integrity [29]. While, in this study, the

314 enhancement of methane production in nZVI added systems indicated that even if cell

315 disruption occurred in studied reactors, functional microbes involved in

316 methanogenesis were not disrupted, and the increased soluble COD would be

317 consumed by anaerobic microorganism to partly enhance the methane generation. In

318 non- nZVI added systems, reactors with TC dosed showed significant higher methane

319 yield potential values than blanks (such as $28-30>18.85 \mathrm{NmLCH}_{4} / \mathrm{gCOD}$ ), it

320 indicated the positive effect of $\mathrm{TC}$ on $\mathrm{CH}_{4}$ production occurred, but it was closely

321 related to the TC concentration (Table 2). This was reasonable that high TC

322 concentration has negative effect on the activity of anaerobic microorganism [26]. 
323 Whereas, the promoting effect of nZVI on methane production in TC wastewater

324 treatment system was independent on TC concentration, even in high concentration of

$325150 \mathrm{mg} / \mathrm{L}$ with cumulative methane production and increased factor of $162.10 \mathrm{NmL}$

326 and 4.87, respectively. Therefore, it could be concluded that nZVI has positive effect

327 on anaerobic TC wastewater treatment, and the promoting effect was not affected by

328 the concentration of antibiotics.

329 At the same time, the TC was biodegraded in studied batch reactors and the

330 removal rate results were presented in Fig. 2, which showed that the removal rates

331 varied from $68 \%$ to $98 \%$. Besides, the TC degradation rates in all systems were higher

332 than $90 \%$ except the system with TC concentration of $1 \mathrm{mg} / \mathrm{L}$. The high TC removal

333 rates of non-added nZVI reactors revealed that TC could be biodegraded by

334 microorganism in studied granular system. Previous study also reported that TC could

335 be degraded by $70 \%$ during polit-scale composting experiment [30]. Although

336 Cetecioglu et al. found a biodegradation rate of $46 \%$ for TC under methanogenic

337 condition [13], Cetecioglu et al. [20] also showed the major fraction ( $>80 \%)$ of the

338 TC introduced into the anaerobic reactor could be fully or partially biodegraded along

339 with the organic substrate. The high removal rates of TC in studied anaerobic reactors

340 could be resulted from the granular sludge which owned higher tolerance to TC than

341 disrupted sludge [16]. In addition, it also might be caused by the activity of

342 microorganism, which had a certain capacity for TC removal without relation to TC

343 concentration. And the residue of TC mainly adsorbed by granular sludge, accounting 
344 for more than $95 \%$ of the total remaining TC, and very little concentration of TC

345 detected in liquid phase (Fig. 2). This result was similar to previous finding that TC

346 showed a strong sorption to biosolids such as soil or activated sludge [31].

347 The effect of nZVI on degradation and adsorption of TC has been reported by

348 Chen et al. [32]. The degradation products mainly included the 4-epi-TC and loss of

349 amine and water as TC-like matter. The iron (hydroxyl) oxides were transformed from

350 nZVI in solution, and then adsorb the TC. The TC is an efficient chelating agent for

351 metal ions with high valet, which would chelate with the iron ion as Fe-TC complex

352 in solution [33]. This could explain the higher removal rates of TC in nZVI dosed

353 systems. Fu et al. [10] obtained 99\% TC removal rate when $500 \mathrm{mg} / \mathrm{L} \mathrm{TC}$ was

354 processed with $0.2 \mathrm{~g} / \mathrm{L}$ nZVI. In addition, during the process of acidogenesis, the $\mathrm{pH}$

355 value in reactors decreased, and the released $\mathrm{H}^{+}$would result in the corrosion of nZVI

356 and producing more active hydrogen $\left(\mathrm{H}^{\circ}\right)$ for reducing $\mathrm{TC}$ with oxidizing $\mathrm{Fe}^{0}$ to $\mathrm{Fe}^{2+}$

$357\left(\mathrm{Fe}^{0}+\mathrm{RX}+\mathrm{H}^{+}-. \mathrm{Fe}^{2+}+\mathrm{RH}+\mathrm{X}^{\prime \prime}\right)[34]$. The release of $\mathrm{Fe}^{2+}$ also supported the ORP

358 increase in nZVI added systems as mentioned in 3.1.

359 As can be seen from the Fig. 2 that the nZVI enhanced the TC removal, but the

360 improvement of TC removal rates in nZVI added systems were not obvious, with

361 enhanced removal rates lower than $4 \%$, expected that in system with $1 \mathrm{mg} / \mathrm{L} \mathrm{TC}$ added

362 of $8.7 \%$. Because the TC removal rates in non-nZVI system were relatively high, and

363 the difference of TC removal rates between nZVI and non-nZVI added systems was

364 slight. It indicated that TC could be efficiently biodegraded in studied granular 
366 technique for both TC removal and organic matters degradation.

\subsection{Succession of microbial community structures}

The relative abundance of bacteria and archaea phylum was calculated based on archaea order (genus) (relative abundance $>2 \%$ ) of the microbial communities,

371 respectively.

\subsubsection{Effect of TC concentration on diversity and abundance of bacteria and}

Diversity and abundance of Bacteria: Fig. 3a and Fig.3b showed the bacterial

375 diversity and abundance in original granular sludge and granules in experimental

376 reactors on order and genus level. The microbial structure of the two originals was

377 quite similar because of the same source of original granules with only different

378 sampling time. While, big difference of microbial diversity and abundance occurred

379 between blank1 and blank 2. Compared to original 1, Atribacteria instead of

380 Bacteroidetes served as dominant bacteria in blank 1 system, which indicated that

381 microbial structure shifted with incubation. In blank 2, Clostridiales turned to be the

382 predominant bacteria. The variation between blank 1 and blank 2 could explain the

383 big variation of methane production and COD removal rates between these two

384 systems. 
388 functional bacteria in the process of anaerobic methanogenesis from organic matters,

389 oxidizing the aromatic compounds incompletely to acetate. And it can only use a few

390 kinds of substrates such as propionate and butyrate in co-culture with $\mathrm{H}_{2}$-scavenging

391 partners. Organisms of this group, like S. aciditrophicus and Syntrophus buswellii, are

392 syntrophic butyrate degraders, and several bacteria strains, (such as S. fumaroxidans,

393 S. wolinii, S. pfennigii, S. sulfatireducens, P. thermopropionicum, P. schinkii, $P$.

394 propionicicum, Smithella propionica and Desulfotomaculum thermobenzoicum ssp.

395 Thermosyntrophicum) belonged to Syntrophobacter are propionate-oxidizing bacteria

396 [35]. The abundance of Syntrophobacterales in TC added systems with low

397 concentration (1-80 mg/L) and high concentration (100 mg/L and $150 \mathrm{mg} / \mathrm{L})$ were

398 higher than those in blank 1 and blank 2, which means that the increase abundance of

399 this bacteria could enhance AD process to finally promote methane production. This

400 could give an explanation for the higher methane production in nZVI added systems,

401 since the abundance of Syntrophobacterales had positive correlation with methane

402 production. It was also verified by the results that the higher abundance

403 Syntrophobacterales led to higher methane production, including TC1 to TC80 and

404 nZVI added systems, lower abundance Syntrophobacterales led to lower methane

405 production, including blank 2, $100 \mathrm{mg} / \mathrm{L}$ and $150 \mathrm{mg} / \mathrm{L} \mathrm{TC}$ added systems. Therefore, 
407 partly owing to the increasing abundance of Syntrophobacterales. This result is in

408 agreement with the observations made by Kong et al. [15], who reported that

409 supplementation of ZVI has a positive effect on the syntrophic microorganism in AD

410 reactor treating solid waste. In addition, Meng et al. [36] found that ZVI addition into

411 an anaerobic reactor increased the propionate degradation rate compared to the

412 control.

413 On the genus level, we can observe that nZVI added systems had quite similar

414 microbial structure, which means that nZVI could change the microbial diversity and

415 abundance independent on the concentration of TC. Syntrophohabdus significantly

416 increased in all nZVI added systems compared to original and non-nZVI systems.

417 Therefore, syntrophic bacteria could be served as an important index for evaluating

418 the performance of AD.

419 Diversity and abundance of Archaea: In original system, Methanobacteriales

420 was predominant methanogens with proportion of $86 \%$, and Methanosarcinales also

421 occupied a certain proportion about 7\%, while Methanomicrobiales only owned taken

422 up lower than $1 \%$. After incubation, the structure of archaea clearly changed. In the

423 first set experiment (contains blank 1, TC concentration from 1 to $80 \mathrm{mg} / \mathrm{L}$ ), the

424 relative abundance of Methanosarcinales increased and turned to be the predominant

425 methanogens with proportion of $63.55 \%-77.02 \%$ in these systems. While in second

426 experimental set (including blank 2, TC concentration of 100 and $150 \mathrm{mg} / \mathrm{L}$ ), the 
Methanobacteriales was still the predominant methanogens (Fig 3c and Fig. 3d).

429 What was interesting, the archaea structure and abundance in blank2 with nZVI added

430 and $100 \mathrm{mg} / \mathrm{L}$ and $150 \mathrm{mg} / \mathrm{L} \mathrm{TC}$ systems with nZVI were quite similar to those in

431 blank 1 and TC (1-80). Cetecioglu et al., [20] found that methanogens and archaea

432 were not affected by TC in an anaerobic reactor after 120 days incubation with TC

433 concentration of $90 \mathrm{ppm}$. It means nZVI addition could shift microbial structure and

434 abundance, which has nothing to do with the concentration of TC. This finding could

435 give an explanation for the similar methane production in different concentration of

436 TC added systems.

437 In fact, there is an intrinsic link between the communities' structure between

438 bacteria and archaea. As showed in Fig.3c, Methanobacteriales, instead of

439 Methanosarcinales, dominated in systems of orginal_1\&2, TC100, TC150 and Blank2,

440 where Anaerolineales showed relative lower percentages than other systems (Fig.3a).

441 Since acetate producer Anaerolineaceae and acetoclastic methanogen Methanosaeta

442 are syntrophs in the acetoclastic pathway [37]. In addition, the high relative

443 abundance of Methanosarcinales in systems of TC1-TC80 and Blank1 might result

444 from the high abundance of Aribacteria, another acetate producer [38].

\subsubsection{Effect of nZVI on microbial structure and syntrophic association}

Fig. 4 described the effect of nZVI addition on the shift of microbial structure on

447 genus level (including bacteria and archaea). It was observed that the 
449 Atribacteria and increase of Anaerolineaceae. In addition, the abundance of

450 Syntrophorhabdus, Syntrophbacter and Syntrophaceae, which plays an important

451 role in the degradation of VFAs (butyrate and propionate) and providing sufficient

452 substrates for methanogens during AD process, all had significant increase in nZVI

453 dosed systems. This result provided an explanation for the enhancement of methane

454 production in nZVI added system. In addition, the proportion of Methanosaeta in

455 nZVI added system increased while Methanobacterium decreased in nZVI added

456 systems. Previous study found that nZVI addition could inhibit hydrogenotrophic

457 methanogenesis due to the rapid hydrogen production during the dissolution of nZVI

458 [39]. This result is in agreement with the observation of Zhang et al. [5], who

459 reported that Methanosaeta abundance increased from $33.81 \%$ to $57.33 \%$, while the

460 abundances of Methanobacterium reduced from $26.98 \%$ to $15.31 \%$ after GAC/nZVI

461 addition. Methanosaeta was strict anaerobe and could only use acetic acid as the

462 substrate to produce methane, while Methanobacterium was hydrogen nutritional

463 methanogens which could produce methane by reducing $\mathrm{CO}_{2}$ with $\mathrm{H}_{2}$ and formic

464 acid. In nZVI added systems, the abundance of Syntrophus (typical

465 hydrogen-producing acetogenic bacteria using butyric acid) increased (mentioned

466 above), resulting in accumulation of acetic acid, which would promote the growth of

467 Methanosaeta and then consumed more acetic acid. It was known that Methanosaeta

468 was also positively correlated with methane production. 
470 without TC and nZVI, blank system with nZVI, systems with TC addition and

471 systems with both TC and nZVI addition (Fig. 5). The results revealed that,

472 compared to TC added systems, the proportion of Anaerolineaceae, Gaiellales,

473 Chloroflexi and syntrophic bacteria including Syntrophorhabdus and Syntrophaceae

474 has significant higher abundance than theses bacteria in non-TC added system $(P$ -

475 value $<0.05$ ). In addition, Methanosaeta also has a higher abundance in nZVI and TC

476 added systems than only TC added systems. The increasing abundance of

477 syntrophic-methanogenic associations might be a reason for that nZVI enhanced

478 methane production in TC added systems. This result is in agreement with the

479 observations made by Kong et al. [15], who reported that supplementation of ZVI has

480 a positive effect on the syntrophic microorganism in an organic fraction of municipal

481 solid waste AD rector, and syntrophic association among the microbial genera of

482 Syntrophomonas, C. butyricum and Methanosarcinales in ZVI dosed systems plays a

483 significant role both in acidification elimination and $\mathrm{CH}_{4}$ production promotion.

484 Combining the communities' structure analysis of bacteria and archaea, we

485 found that nZVI addition could change the microbial community's structure, and the

486 increasing abundance of syntrophic-methanogenic associations (Syntrophobacterales

487 and Methanosarcinales) contributed to high methane production. Previous study used

488 to focus on the change of dominant groups [5], and ignored the key microbial with a

489 relative low abundance but playing an important role in AD process, such as 
syntrophic fatty acids oxidizing bacteria (SFOB). SFOB constitute a 'keystone' guild,

491 i.e., organisms whose impact on community structure and function is far greater than

492 what their abundance would suggest [40]. Meanwhile, Syntrophobacterales plays an

493 important role in $\mathrm{AD}$ process, but it is still not valued in the study focusing on

494 wastewater degradation. Thus, it is necessary to deepen the understanding of its

495 functions and further establish engineering control strategies in the future.

496

\subsubsection{Effect of TC on microbial structure}

As mentioned above, TC addition also had positive effect on methane production.

Compared with the blank systems, the proportion of Anaerolineaceae, Chloroflexi, Syntrophorhabdus and Syntrophaceae had significant increase $(P$-value $<0.05)$ (Fig.

5). Meanwhile, the abundance of Methanosaeta in TC added systems was higher than it in blank system, while Methanobacterium presented a lower level in TC added system than in blank systems. As discussed above, these shift of bacteria and archaea contributes to the promotion of $\mathrm{AD}$ process in $\mathrm{TC}$ added systems.

In conclusion, both $\mathrm{nZVI}$ and TC addition have significant effect on microbial community succession, in turn, influencing AD performance, including COD removal and methane generation. Therefore, the enhancement of methane production by nZVI and TC might due to the change of microbial structure with increasing the abundance of functional microorganism, like syntrophic association, during AD process, which provides a biological basis and technological supports for enhancing the treatment efficiency from TC wastewater in AD process. 


\section{Conclusions}

The addition of nZVI is an effective technology to improve TC degradation and

513 methane production in anaerobic process. TC removal rates reached over $90 \%$ in most

514 systems expect the the reactors with TC concentration of $1 \mathrm{mg} / \mathrm{L}$. Interestingly, TC also

515 had positive effect instead of expected negative effect on $\mathrm{AD}$, even with high TC

516 concentration of 100 and $150 \mathrm{mg} / \mathrm{L}$. The high dosage of TC addition just affected the

517 increase factors methanogenesis rather than causing inhibition. nZVI evidently altered

518 the bacterial and methanogenic community structure, with an increase abundance of

519 syntrophic-methanogenic associations (Syntrophobacterales and Methanosarcinales)

520 and resulting in the promotion of methane production. The results would provide the

521 theoretical basis and technological supports for enhancing the treatment efficiency and

522 energy recovery from TC wastewater in AD process.

\section{Acknowledgements}

525 The authors would like to thank the National Key Research and Development Program

526 of China (Contract No.2017YFD0800804-03, 2018YFD0500202-04), the National

527 Natural Science Foundation of China (Contract No. 21477122, 51678553, 21276248,

$52851808525,21876167)$, the Project of the Natural Science Foundation of Fujian

529 Province (Contract No.2016J01273, 2017J05092), the Xiamen Science and

530 Technology Project (Contract No. 3502Z20182003), IUE CAS Young Talents Frontier 


\section{References}

[2] M.M. Amin, J.L. Zille, J. Greiner, S. Charbonneau, L. Raskin, E. Morgenroth,

539 Influence of the antibiotic erythromycin on anaerobic treatment of a pharmaceutical

540 wastewater, Environ. Sci. Technol. 40 (2006) 3971-3977.

$541 \quad$ https://doi.org/10.1021/es060428j

542 [3] J.Wang, X. Jiang, X. Liu, X. Sun, W. Han, J. Li, Microbial degradation mechanism

543 of pyridine by paracoccus, $s p$. NJUST 30 newly isolated from aerobic granules,

544 Chem. Eng. J. 344 (2018) 86-94. https://doi.org/10.1016/j.cej.2018.03.059

545 [4] X. Zhou, W. Jin, C. Sun, S.H. Gao, C.Chen, Q.Wang, Microbial degradation of

546 n,n-dimethylformamide by paracoccus, sp. strain DMF-3 from activated sludge,

547 Chem. Eng. J. 343 (2018) 324-330. https://doi.org/10.1016/j.cej.2018.03.023

548 [5] Z. Zhang, P. Gao, J. Cheng, G. Liu, X. Zhang, Y. Feng, Enhancing anaerobic

549 digestion and methane production of tetracycline wastewater in EGSB reactor with 550 gac/nZVI mediator, Water Res. 136 (2018) 54-63. 
552 [6] S. Chelliapan, T. Wilby, P.J. Sallis, Performance of an up-flow anaerobic stage

553 reactor (UASR) in the treatment of pharmaceutical wastewater containing macrolide

554 antibiotics, Water Res. 40 (2006) 507-516.

555 https://doi.org/10.1016/j.watres.2005.11.020

556 [7] A. Spielmeyer, B. Breier, K. Groißmeier, G Hamscher, Elimination patterns of

557 worldwide used sulfonamides and tetracyclines during anaerobic fermentation,

558 Bioresour. Technol. 193 (2015) 307-314.

559 https://doi.org/10.1016/j.biortech.2015.06.081

560 [8] J.Y. Ji, Y.J. Xing, Z.T. Ma, J. Cai, P. Zheng, H.F. Lu, Toxicity assessment of

561 anaerobic digestion intermediates and antibiotics in pharmaceutical wastewater by

562 luminescent bacterium, J. Hazard. Mater. 246 (2013) 319-323.

563 https://doi.org/10.1016/j.jhazmat.2012.12.025

564 [9] M. Lu, X. Niu, W. Liu, J. Zhang, J. Wang, J. Yang, W. Wang, Z. Yang, Biogas

565 generation in anaerobic wastewater treatment under tetracycline antibiotic pressure,

566 Sci. Re. 6 (2016) 28336. https://doi.org/10.1038/srep28336

567 [10] Y. Fu, L. Peng, Q. Zeng, Y. Yang, H. Song, J. Shao, High efficient removal of

568 tetracycline from solution by degradation and flocculation with nanoscale zero valent

569 iron, Chem. Eng. J. 270 (2015) 631-640. https://doi.org/10.1016/j.cej.2015.02.070

570 [11] J. Cao, Z. Xiong, B. Lai, Effect of initial $\mathrm{pH}$ on the tetracycline (TC) removal by

571 zero-valent iron: adsorption, oxidation and reduction, Chem. Eng. J. 343(2018) 

492-499. https://doi.org/10.1016/j.cej.2018.03.036

[12] Y. Zhang, Y. Jing, X. Quan, Y. Liu, P. Onu, A built-in zero valent iron anaerobic reactor to enhance treatment of azo dye wastewater, Water Sci. Technol. 63 (2011) 741-746. https://doi.org/10.2166/wst.2011.301

[13] W.Wei, Z.Cai, J. Fu, G.J. Xie, A. Li, X. Zhou, Zero valent iron enhances methane production from primary sludge in anaerobic digestion, Chem. Eng. J. 351(2018) 1159-1165 https://doi.org/10.1016/j.cej.2018.06.160

[14] Y.W. Liu, Y.B. Zhang, X. Quan, S. Chen, H.M. Zhao, Applying an electric field in a built-in zero valent iron-anaerobic reactor for enhancement of sludge granulation, Water Res. 45 (2011) 1258-1266. https://doi.org/10.1016/j.watres.2010.10.002

[15] X. Kong, S. Yu, W. Fang, J. Liu, H. Li, Enhancing syntrophic associations among clostridium butyricum, syntrophomonas and two types of methanogen by zero valent iron in an anaerobic assay with a high organic loading, Bioresour. Technol. 257 (2018) 181.https://doi.org/10.1016/j.biortech.2018.02.088

[16] J. Du, Y. Hu, W. Qi, Y. Zhang, Z. Jing, M. Norton, Influence of four antimicrobials on methane-producing archaea and sulfate-reducing bacteria in anaerobic granular sludge, Chemosphere. 140 (2015) 184-190.

https://doi.org/10.1016/j.chemosphere.2014.08.028

[17] American Public Health Association (APHA), Standard Methods for the Examination of Water and Wastewater, $21^{\text {st }}$ ed., American Public Health Association, Washington, DC, 2005. 
593 [18] I. Angelidaki, W. Sanders, Assessment of the anaerobic biodegradability of

594 macropollutants, Rev Environ Sci Bio. 3(2004) 117-129.

595 https://doi.org/10.1007/s11157-004-2502-3

596 [19] J.Q. Chen, Research on the enhanced process and performance during anaerobic 597 digestion of tetracycline wastewater by redox mediator, Doctoral dissertation, Harbin $598 \quad$ Institute of Technology. 2016.

599 [20] Z. Cetecioglu, B. Ince, M. Gros, S. RodriguezMozaz, D. Barceló, D. Orhon, O. 600 Ince, Chronic impact of tetracycline on the biodegradation of an organic substrate

601 mixture under anaerobic conditions, Water Res. 47(2013) 2959-2969.

602 https://doi.org/10.1016/j.watres.2013.02.053

$603[21]$ N. Xu, G. Tan, H. Wang, Effect of biochar additions to soil on nitrogen leaching, 604 microbial biomass and bacterial community structure, Eur. J. Soil Biol. 74 (2016) 1-8.

605 https://doi.org/10.1016/j.ejsobi.2016.02.004

606 [22] C. Liu, H. Li, Y. Zhang, Evolution of microbial community along with increasing 607 solid concentration during high-solids anaerobic digestion of sewage sludge,

608 Bioresour. Technol. 216 (2016) 87-94. https://doi.org/10.1016/j.biortech.2016.05.048

609 [23] S. Bolado-Rodríguez, C.Toquero, J. Martín-Juárez, R. Travaini, P.A.

610 García-Encina, Effect of thermal, acid, alkaline and alkaline-peroxide pretreatments

611 on the biochemical methane potential and kinetics of the anaerobic digestion of wheat

612 straw and sugarcane bagasse, Bioresour. Technol. 201 (2016) 182-190.

613 http://dx.doi.org/10.1016/j.biortech.2015.11.047. 
614 [24] X.F Pan, I. Angelidaki, M. Alvarado-Morales, H.G Liu, Y.H Liu, X Huang, G.F

615 Zhu, Methane production from formate, acetate and $\mathrm{H} 2 / \mathrm{CO} 2$; focusing on kinetics

616 and microbial characterization, Bioresour. Technol. 218 (2016) 796-806. doi:

$617 \quad$ 10.1016/j.biortech.2016.07.032

618 [25] T. Jia, Z. Wang, H. Shan, Y. Liu, L. Gong, Effect of nanoscale zero-valent iron on

619 sludge anaerobic digestion, Resour. Conserv. 127 (2017) 190-195.

620 [26] A.G. Mohamed, K.A. Nageh, Impact of nanotechnology on biogas production: a

621 mini-review, Renewable Sustainable Energy Rev. 50 (2015) 1392-1404.

622 https://doi.org/10.1016/j.rser.2015.05.073

623 [27] X.Q. Li, D.G. Brown, Stabilization of biosolids with nanoscale zero-valent iron

624 (nZVI), J. Nanopart. Res. 9 (2007) 233-243.

625 https://doi.org/10.1007/s11051-006-9187-1

626 [28] J.C. Shi, X.D. Liao, Y.B. Wu, J.B. Liang, Effect of antibiotics on methane arising

627 from anaerobic digestion of pig manure, Anim. Feed Sci. Tech. 166 (2011) 457-463.

628 https://doi.org/10.1016/j.anifeedsci.2011.04.033

629 [29] Y. Yang, J. Guo, Z. Hu, Impact of nano zero valent iron (nZVI) on methanogenic

630 activity and population dynamics in anaerobic digestion, Water Res. 47 (2013) 6790.

631 https://doi.org/10.1016/i.watres.2013.09.012

632 [30] X. Wu, Y. Wei, J. Zheng, X. Zhao, W. Zhong, The behavior of tetracyclines and

633 their degradation products during swine manure composting, Bioresour. Technol.

634102 (2011) 5924-5931. https://doi.org/10.1016/j.biortech.2011.03.007 
635 [31] N. Prado, J. Ochoa, A. Amran, Biodegradation and biosorption of tetracycline 636 and tylosin antibiotics in activated sludge system, Process Biochem. 44 (2009) 1302-

637 1306. https://doi.org/10.1016/j.procbio.2009.08.006

638 [32] H. Chen, H. Luo, Y. Lan, T. Dong, B. Hu, Y. Wang, Removal of tetracycline from 639 aqueous solutions using polyvinylpyrrolidone (PVP-K30) modified nanoscale zero

640 valent iron, J. Hazard. Mater. 192 (2011) 44-53.

641 https://doi.org/10.1016/i.jhazmat.2011.04.089

642 [33] D. Grenier, M.P. Huot, D. Mayrand, Iron-chelating activity of tetracyclines and

643 its impact on the susceptibility of ctinobacillus actinomycetemcomitans to these

644 antibiotics, Antimicrob. Agents Chemother. 44 (2000) 763-767.

645 https://doi.org/10.1128/aac.44.3.763-766.2000

646 [34] L.J. Matheson, P.G. Tratnyek, Reductive dehalogenation of chlorinated methanes

647 by iron metal, Environ. Sci. Technol. 28 (1994) 2045-2053.

648 https://doi.org/10.1021/es00061a012

649 [35] N. Müller, P. Worm, B. Schink, A. J. Stams, C.M. Plugge, Syntrophic butyrate

650 and propionate oxidation processes: from genomes to reaction mechanisms, Env.

651 Microbiol. Rep. 2 (2010) 489-499. https://doi.org/10.1111/j.1758-2229.2010.00147.x

652 [36] X. Meng, Y. Zhang, Q. Li, X. Quan, Adding FeO powder to enhance the

653 anaerobic conversion of propionate to acetate, Biochem Eng J. 73 (2013) 80-85.

654 https://doi.org/10.1016/j.bej.2013.02.004

655 [37] Z. Zhao, Y. Zhang, D.E. Holmes, Y. Dang, T.L. Woodard, K.P. Nevin, D.R. 
656 Lovley, Potential enhancement of direct interspecies electron transfer for syntrophic

657 metabolism of propionate and butyrate with biochar in up-flow anaerobic sludge

658 blanket reactors, Bioresour. Technol. 209 (2016) 148-156.

659 https://doi.org/10.1016/j.biortech.2016.03.005

660 [38] S.A. Carr, B.N. Orcutt, K.W. Mandernack, J.R. Spear, Abundant Atribacteria in

661 deep marine sediment from the adélie basin, Antarctica, Front Microbiol. 6 (2015)

662 872. https://doi: 10.3389/fmicb.2015.00872.

663 [39] Y. Yang, C. Zhang, Z. Hu, Impact of metallic and metal oxide nanoparticles on

664 wastewater treatment and anaerobic digestion, Environ. Sci. Process Impacts. 15

665 (2013) 39-48. https://doi.org/10.1039/c2em30655g

666 [40] M.E. Power, D. Tilman, J.A. Estes, B.A. Menge, W.J. Bond, L.S. Mills, G. Daily,

667 J.C. Castilla, J. Lubchenco, R. Paine, Challenges in the quest for keystones,

668 BioScience 46 (1996) 609-620. https://www.jstor.org/stable/1312990

669

670

671

672

673 